\title{
Properties of Negatively Charged Ruthenium Clusters in Molten Sodium Chloride
}

\author{
Rahimi, Nazanin; McFarland, Eric W.; Metiu, Horia; Kristoffersen, Henrik H.
}

Published in:

Journal of Physical Chemistry C

Link to article, DOI:

10.1021/acs.jpcc.9b02616

Publication date:

2019

Document Version

Peer reviewed version

Link back to DTU Orbit

Citation (APA):

Rahimi, N., McFarland, E. W., Metiu, H., \& Kristoffersen, H. H. (2019). Properties of Negatively Charged Ruthenium Clusters in Molten Sodium Chloride. Journal of Physical Chemistry C, 123(26), 16179-16185. https://doi.org/10.1021/acs.jpcc.9b02616

\section{General rights}

Copyright and moral rights for the publications made accessible in the public portal are retained by the authors and/or other copyright owners and it is a condition of accessing publications that users recognise and abide by the legal requirements associated with these rights.

- Users may download and print one copy of any publication from the public portal for the purpose of private study or research.

- You may not further distribute the material or use it for any profit-making activity or commercial gain

- You may freely distribute the URL identifying the publication in the public portal 
This document is confidential and is proprietary to the American Chemical Society and its authors. Do not copy or disclose without written permission. If you have received this item in error, notify the sender and delete all copies.

\section{Properties of Negatively Charged Ruthenium Clusters in} Molten Sodium Chloride

\begin{tabular}{|r|l|}
\hline Journal: & The Journal of Physical Chemistry \\
\hline Manuscript ID & jp-2019-02616z.R1 \\
\hline Manuscript Type: & Article \\
\hline Date Submitted by the & $26-$ May-2019 \\
\hline Complete List of Authors: & $\begin{array}{l}\text { Rahimi, Nazanin; University of California Santa Barbara, } \\
\text { McFarland, Prof. Eric; University of California Santa Barbara, Chemical } \\
\text { Engineering } \\
\text { Metiu, Horia; University of California Santa Barbara, Chemistry \& } \\
\text { Biochemistry } \\
\text { Kristoffersen, Henrik; Danmarks Tekniske Universitet, Department of } \\
\text { Physics }\end{array}$ \\
\hline
\end{tabular}




\title{
Properties of negatively charged ruthenium clusters in molten sodium chloride
}

\author{
Nazanin Rahimi ${ }^{[a]}$, Eric W. McFarland ${ }^{[a]}$, Horia Metiu ${ }^{[b]}$, Henrik H. Kristoffersen*[c]
}

${ }^{a}$ Department of Chemical Engineering, University of California, Santa Barbara, CA 93106-5080, USA

${ }^{\mathrm{b}}$ Department of Chemistry and Biochemistry, University of California, Santa Barbara, CA 93106-9510, USA

${ }^{c}$ Department of Physics, Technical University of Denmark, DK-2800 Kgs. Lyngby, Denmark

*Tel: +45 21459488; E-mail: hhkri@dtu.dk 


\begin{abstract}
Negatively charged ruthenium clusters dispersed in molten $\mathrm{NaCl}$ are studied with density functional theory and molecular dynamics. The Ru clusters are charged by adding additional $\mathrm{Na}$ atoms to the molten salt. We consider $\mathrm{Ru}_{6}{ }^{m-}$ and $2 \mathrm{Ru}_{3}{ }^{m / 2-}$ clusters $(m=0,2,4)$ and investigate the importance of size, charge, and molten $\mathrm{NaCl}$ electrolyte on the stability of the small Ru clusters. Generally, the Ru clusters are not stable in the few atom limit compared to Ru atoms in bulk metallic Ru. However, charging the clusters, increasing their size, and solvating them in molten $\mathrm{NaCl}$ reduces the energy cost substantially. Neutral $\mathrm{Ru}_{6}$ suspended in $\mathrm{NaCl}$ is relatively unreactive towards $\mathrm{N}_{2}$ adsorption, but when charged, the clusters are predicted to be very active for both molecular and dissociative $\mathrm{N}_{2}$ adsorption.
\end{abstract}




\section{Introduction}

Metal nanoparticles suspended in molten salt media ${ }^{1-3}$ can be obtained by reducing their corresponding cations (as halides or oxides) in a mixture with a non-reducible molten salt using hydrogen gas, ${ }^{4}$ or an alkali metal. ${ }^{5-7}$ The reduction potential of alkali metal dissolved in molten alkali halide salts is so large that the alkali atoms ionize to alkali ions and solvated electrons. ${ }^{8-11}$ Consequently, it may be possibly to obtain negatively charged metal nanoparticles suspended in molten alkali halide salts by adding alkali metals to a molten salt that already contains metal nanoparticles in oxidation state 0 . To our knowledge this has not been explored experimentally.

Such negatively charged metal particles could potentially function as a Lewis base catalyst and be useful in industrial applications. ${ }^{12}$ Base catalysts facilitate the formation of negative ion intermediates. ${ }^{13}$ Heterogeneous base catalysts often work by donating electrons to intermediates adsorbed on the surface, and one way to modify the activity is to charge the catalyst particles and thereby affect their ability to donate electrons. Examples are zeolites doped with alkali metal, ${ }^{14,15}$ supported metal clusters promoted with alkali metal, ${ }^{16,17}$ and metal clusters supported on electrides ${ }^{18}$ (i.e. salts where electrons serve as anions).

In this study we use ab initio molecular dynamics (AIMD) to investigate the stability of negatively charged ruthenium clusters in molten sodium chloride and their ability to stabilize negatively charged adsorbates/intermediates. The study builds on a recent study from our group, where the reactivity of solvated electrons was investigated in molten alkali chloride. ${ }^{19}$ When we add the $\mathrm{Ru}$ clusters to the molten $\mathrm{NaCl}$ containing solvated electrons, the electrons move to and negatively charge the $\mathrm{Ru}$ clusters. We specifically study $\mathrm{Ru}_{3}$ and $\mathrm{Ru}_{6}$ clusters in molten $\mathrm{NaCl}$ containing $\mathrm{m}=0,2$, and 4 solvated electrons $\left(m \mathrm{e}^{-}(\right.$solvated $\left.)+m \mathrm{Na}^{+}+45 \mathrm{NaCl}\right)$, which result in charged cluster systems of the form $\mathrm{Ru}_{n}{ }^{m-}+m \mathrm{Na}^{+}+45 \mathrm{NaCl}$. In this way, we construct four 
cases with $\mathrm{Ru}$ clusters of different charges and sizes, namely: (i) $\mathrm{Ru}_{6}+45 \mathrm{NaCl}$, (ii) $\mathrm{Ru}_{6}{ }^{2-}+2 \mathrm{Na}^{+}$ $+45 \mathrm{NaCl}$, (iii) $\mathrm{Ru}_{6}{ }^{4-}+4 \mathrm{Na}^{+}+45 \mathrm{NaCl}$, and (iv) $\mathrm{Ru}_{3}{ }^{2-}+2 \mathrm{Na}^{+}+45 \mathrm{NaCl}$. The $\mathrm{Ru}_{6}{ }^{m-}$ clusters in system (i), (ii), and (iii) are compared to $2 \mathrm{Ru}_{3}{ }^{m / 2-}$ to gain insight into the stability of clusters with different sizes and charges. $\mathrm{N}_{2}$ adsorption on all four clusters is used to probe the reactivity of the clusters.

We find that the Ru clusters with three or six atoms are not stable compared to Ru metal. This is understandable as ruthenium metal has a high cohesive energy. ${ }^{20}$ However, $\mathrm{Ru}_{6}$ is roughly the largest clusters we can investigate with AIMD, when we want the cluster to be solvated in the molten salt. Nevertheless, the stability is affected by molten $\mathrm{NaCl}$, the cluster charge, and its size. This insight will be useful when attempting to synthesize negatively charged $\mathrm{Ru}$ clusters in the nanometer range. It is also possible that very small Ru clusters will be kinetically stable against agglomeration because of their own negative charge or the charge of their solvation shell.

In the gas phase, the adsorption energy of a $\mathrm{N}_{2}$ molecule to a $\mathrm{Ru}_{6}$ cluster is similar to adsorption at step sites on the $\mathrm{Ru}(0001)$ surface. When the $\mathrm{Ru}_{6}$ cluster is moved from the gas phase to the molten $\mathrm{NaCl}$, it loses most of its reactivity, but becomes reactive again when it becomes negatively charged. A scaling relation exists between the molecular adsorption and dissociative adsorption energies of $\mathrm{N}_{2}$ which holds for $\mathrm{Ru}$ clusters in the gas phase, Ru clusters in molten $\mathrm{NaCl}$, and $\mathrm{Ru}$ clusters charged by solvated electrons. The single exception is the $\mathrm{Ru}_{3}{ }^{2-}$ cluster in molten $\mathrm{NaCl}$, which binds molecular $* \mathrm{~N}_{2}$ more weakly than expected. The $* \mathrm{~N}_{2}$ and $2 \mathrm{~N}^{*}$ species always become negatively charged when adsorbed on the Ru clusters.

\section{Computational details}


The computational details follow closely the approach used in the recent study about solvated electrons in molten alkali chloride salts from our group. ${ }^{19}$

The molten $\mathrm{NaCl}$ containing $\mathrm{Ru}_{\mathrm{x}}$ clusters is modeled as free standing films with $45 \mathrm{NaCl}$ units and a thickness of roughly $20 \AA$. The computational cells are $12 \AA \times 12 \AA$ parallel to the molten salt films and $40 \AA$ in the perpendicular direction. The systems are studied with constant temperature AIMD using VASP. ${ }^{21-24}$ The MD simulations utilize density functional theory (DFT) calculations with plane wave basis sets (350 eV energy cutoff) and $\Gamma$-point sampling of reciprocal space. The DFT exchange-correlation effects are approximated by the PBE functional ${ }^{25}$ and the D3 van der Waals correction. ${ }^{26}$ The DFT calculations use the PAW method and include 1, 5, 7, and 8 valence electrons for every $\mathrm{Na}, \mathrm{N}, \mathrm{Cl}$, and $\mathrm{Ru}$ atom, respectively. Spin polarization is included in all calculations and the spin is fixed to the singlet spin state. Fixing the spin to the singlet state is an approximation, since small Ru clusters can be ferromagnetic; ${ }^{27}$ however our MD simulations are conducted at $1100 \mathrm{~K}$, which is likely above the Curie point of our clusters. The $1100 \mathrm{~K}$ is also a little above the melting point of $\mathrm{NaCl}(1074 \mathrm{~K}) .{ }^{28} \mathrm{The}$ temperature is controlled by a Nosé thermostat, ${ }^{29}$ the motion of the atoms is treated classically and time evolution is propagated with $1 \mathrm{fs}$ time steps.

The internal energy, $\langle E\rangle_{t}$, of a given system is calculated as the time average kinetic energy $(K)$ and DFT energy $\left(E_{\mathrm{DFT}}\right)$ from the MD simulation.

$\langle E\rangle_{t}=\frac{1}{t-t_{0}} \int_{t_{0}}^{t} E_{\mathrm{DFT}}(\tau)+K(\tau) d \tau$

The initial part of each MD simulation $\left(t<t_{0}\right)$ is disregarded to equilibrate the system before internal energy sampling is conducted. The $t_{0}$ value for each simulation is chosen such that any 
initial internal energy transient is removed. As the $\mathrm{Ru}_{\mathrm{x}}$ clusters (with and without $* \mathrm{~N}_{2} / 2 \mathrm{~N} *$ ) are initially placed at the vacuum molten $\mathrm{NaCl}$ interface, $t_{0}$ roughly coincides with the time it takes for the molten $\mathrm{NaCl}$ to properly solvate the cluster. The molten salt systems are subsequently sampled for 11 to $19 \mathrm{ps}$. The $t_{0}$ values and sampling times $\left(t-t_{0}\right)$ for the individual molten salt simulations are listed in Supporting Information (Table S1). The Supporting Information also contains movies showing the full trajectories of the MD simulations with Ru clusters in molten $\mathrm{NaCl}$.

We have calculated reaction energies as internal energy differences. For example, the adsorption energy of a $\mathrm{N}_{2}$ molecule, $E_{\text {ad }}$, adsorbed on $\mathrm{Ru}_{n}{ }^{m \text { - }}$ is calculated as the internal energy of the system with adsorbed $\mathrm{N}_{2}\left(\left\langle E_{\mathrm{N}_{2}}+\mathrm{Ru}_{n}^{m-}\right\rangle_{t}\right)$, minus the internal energy of the $\mathrm{Ru}_{n}{ }^{m-}$ cluster alone in the molten salt $\left(\left\langle E_{\mathrm{Ru}_{n}^{m}-}\right\rangle_{t}\right)$, minus the internal energy of the $\mathrm{N}_{2}$ molecule alone in the gas-phase $\left(\left\langle E_{\mathrm{N}_{2}(\mathrm{~g})}\right\rangle_{t}+\frac{3}{2} k_{B} T\right)$. The $3 / 2 k_{\mathrm{B}} T$ term is added to the internal energy of the gas-phase molecule because the center-of-mass motion is not included in the MD simulation.

$E_{\mathrm{ad}}=\left\langle E_{\mathrm{N}_{2}}+\mathrm{Ru}_{n}^{m-}\right\rangle_{t}-\left\langle E_{\mathrm{Ru}_{n}^{m}-}\right\rangle_{t}-\left(\left\langle E_{\mathrm{N}_{2}(\mathrm{~g})}\right\rangle_{t}+\frac{3}{2} k_{B} T\right)$

In the Supporting Information we have plotted cumulative reaction energies as a function of sampling time (running averages) (Figure S1 and Figure S2). These plots also show the degree of internal energy convergence for the individual AIMD simulations.

An important part of this study is the effect of solvated electrons on the stability of $\mathrm{Ru}_{3}$ and $\mathrm{Ru}_{6}$ clusters and the clusters reactivity towards a $\mathrm{N}_{2}$ molecule. We have therefore calculated atomic Bader charges ${ }^{30-32}$ to track the location of these electrons. Bader charges are calculated 
for atomic configurations taken with 1 ps intervals along the MD trajectories and the average values reported.

\section{Results and Discussion}

3.1 Stability of $\mathbf{R u}_{n}{ }^{m-}$ clusters. Ru has a high cohesive energy and we find that the clusters of three or six Ru atoms are not stable compared to Ru metal. However, moving the Ru clusters between gas phase and molten $\mathrm{NaCl}$ media and changing the charge and size of the clusters affects the stability significantly (Table 1).

Formation of a gas phase $\mathrm{Ru}_{6}$ cluster from $\mathrm{Ru}$ metal requires $20.8 \mathrm{eV}$, while breaking the $\mathrm{Ru}_{6}$ cluster into two gas phase $\mathrm{Ru}_{3}$ clusters adds an additional $8.0 \mathrm{eV}$. The energy required for cluster formation is significantly lowered when the clusters are solvated in molten $\mathrm{NaCl}$. Forming a $\mathrm{Ru}_{6}$ cluster in molten $\mathrm{NaCl}$ from bulk Ru requires $14.7 \mathrm{eV}$, while breaking $\mathrm{Ru}_{6}$ into two $\mathrm{Ru}_{3}$ in the molten $\mathrm{NaCl}$ requires an additional $6.1 \mathrm{eV}$. The molten $\mathrm{NaCl}$ stabilizes two $\mathrm{Ru}_{3}$ clusters more than the $\mathrm{Ru}_{6}$ cluster, but not nearly enough to favor $2 \mathrm{Ru}_{3}$ over $\mathrm{Ru}_{6}$.

In molten $\mathrm{NaCl}$ containing solvated electrons the $\mathrm{Ru}_{6}$ cluster becomes negatively charged (formally written as reaction eq 3).

$6 \mathrm{Ru}(\mathrm{s})+m \mathrm{e}^{-}($solvated $)+m \mathrm{Na}^{+}+45 \mathrm{NaCl} \rightarrow \mathrm{Ru}_{6}{ }^{m-}+m \mathrm{Na}^{+}+45 \mathrm{NaCl}$

The solvated electrons are very reactive, ${ }^{19}$ but surprisingly, moving two solvated electrons to $\mathrm{Ru}_{6}$ and forming $\mathrm{Ru}_{6}{ }^{2-}$ (Bader charge on $\mathrm{Ru}_{6}{ }^{2-}$ is -1.37 e) does not lower the energy cost $(14.8 \mathrm{eV}$, Table 1) compared to formation of the neutral $\mathrm{Ru}_{6}$ in molten $\mathrm{NaCl}(14.7 \mathrm{eV}$ ) (Bader charge on $\mathrm{Ru}_{6}$ is $-0.34 e$ ). Transferring four solvated electrons and forming $\mathrm{Ru}_{6}{ }^{4-}$ does lower the energy cost substantially $(13.1 \mathrm{eV})$ (Bader charge on $\mathrm{Ru}_{6}^{4-}$ is $-2.17 e$ ). 
In addition to $\mathrm{Ru}_{6}, \mathrm{Ru}_{6}{ }^{2-}$, and $\mathrm{Ru}_{6}{ }^{4-}$, we have also considered $2 \mathrm{Ru}_{3}, 2 \mathrm{Ru}_{3}{ }^{-}$, and $2 \mathrm{Ru}_{3}{ }^{2-}$ to obtain the energy required to break $\mathrm{Ru}_{6}{ }^{m-}$ clusters into $2 \mathrm{Ru}_{3}{ }^{m / 2-}$ as a function of charge (Table 1 ). These MD simulations are initialized by placing one $\mathrm{Ru}_{3}{ }^{\mathrm{m} / 2-}$ cluster at the upper surface and the other $\mathrm{Ru}_{3}{ }^{m / 2-}$ cluster at the bottom surface of the molten $\mathrm{NaCl}$ film. We originally had the preconception that highly negatively charged $\mathrm{Ru}$ clusters would be prone to breaking into two clusters in order to lower the total electron-electron repulsion. However, the results in Table 1 show that electron-electron repulsion is not very important as the reaction energies for $\mathrm{Ru}_{6} \rightarrow$ $2 \mathrm{Ru}_{3}, \mathrm{Ru}_{6}{ }^{2-} \rightarrow 2 \mathrm{Ru}_{3}{ }^{-}$, and $\mathrm{Ru}_{6}^{4-} \rightarrow 2 \mathrm{Ru}_{3}{ }^{2-}$ only decrease a little with increasing charge $(6.1 \mathrm{eV}$ $5.6 \mathrm{eV}$, and $5.7 \mathrm{eV}$, respectively).

Table 1. Stability of Ru clusters compared to $\mathrm{Ru}(\mathrm{s})$. Listed are the reaction energies to form $\mathrm{Ru}_{6}{ }^{m-}\left(\Delta E_{l}\right)$ and the reaction energies to form $2 \mathrm{Ru}_{3}{ }^{m / 2-}\left(\Delta E_{1+2}\right)$ from $6 \mathrm{Ru}(\mathrm{s})$ and $m$ solvated electrons:

$6 \mathrm{Ru}(\mathrm{s})+m \mathrm{e}^{-} \rightarrow \mathrm{Ru}_{6}{ }^{m-} \rightarrow 2 \mathrm{Ru}_{3}{ }^{m / 2-}$

\begin{tabular}{|l|c|c|c|}
\hline $\mathbf{R u}_{\mathbf{6}}{ }^{\boldsymbol{m}-} / \mathbf{2} \mathbf{R u}_{3}{ }^{\boldsymbol{m} / 2-}$ & Reaction media & $\Delta \boldsymbol{E}_{\boldsymbol{l}}$ & $\Delta \boldsymbol{E}_{\boldsymbol{I + 2}}$ \\
\hline $\mathrm{Ru}_{6} / 2 \mathrm{Ru}_{3}$ & gas phase & $20.8 \mathrm{eV}$ & $28.8 \mathrm{eV}$ \\
\hline $\mathrm{Ru}_{6} / 2 \mathrm{Ru}_{3}$ & molten NaCl & $14.7 \mathrm{eV}$ & $20.7 \mathrm{eV}$ \\
\hline $\mathrm{Ru}_{6}{ }^{2-} / 2 \mathrm{Ru}_{3}^{-}$ & molten NaCl & $14.8 \mathrm{eV}$ & $20.3 \mathrm{eV}$ \\
\hline $\mathrm{Ru}_{6}{ }^{4-} / 2 \mathrm{Ru}_{3}{ }^{2-}$ & molten NaCl & $13.1 \mathrm{eV}$ & $18.8 \mathrm{eV}$ \\
\hline
\end{tabular}


3.2 Interactions between $\mathrm{Ru}_{n}{ }^{m \text { - }}$ clusters and $\mathrm{NaCl}$. In order to understand the interactions between molten $\mathrm{NaCl}$ and $\mathrm{Ru}$ clusters of different charge and size, we have constructed radial distribution functions $(\mathrm{g}(r))$ from the MD trajectories of $\mathrm{Ru}_{6}+45 \mathrm{NaCl}, \mathrm{Ru}_{6}{ }^{2-}+2 \mathrm{Na}^{+}+45 \mathrm{NaCl}$, $\mathrm{Ru}_{6}{ }^{4-}+4 \mathrm{Na}^{+}+45 \mathrm{NaCl}$, and $\mathrm{Ru}_{3}{ }^{2-}+2 \mathrm{Na}^{+}+45 \mathrm{NaCl}$ (Figure 1). We note that the MD simulation for $\mathrm{Ru}_{3}{ }^{2-}+2 \mathrm{Na}^{+}+45 \mathrm{NaCl}$ is different from the one conducted for the system with $2 \mathrm{Ru}_{3}{ }^{2-}$ discussed in section 3.1 .

In the $\mathrm{Ru}_{6}+45 \mathrm{NaCl}$ simulation (Figure 1a), $\mathrm{g}(r)$ for $\mathrm{Ru}-\mathrm{Cl}$ has a sharp peak at $2.4 \AA$, which shows that the inner solvation shell around $\mathrm{Ru}_{6}$ mainly consists of $\mathrm{Cl}^{-}$ions. The area of the peak ( $r<3 \AA$, Table 2) correspond to $0.98 \mathrm{Cl}^{-}$neighbors per $\mathrm{Ru}$ atom and visual inspection of the atomic configurations show that each $\mathrm{Ru}$ atom binds a single $\mathrm{Cl}^{-}$ion. The $\mathrm{Ru}-\mathrm{Cl}^{-}$interactions are partially covalent in nature, which moves electrons to the $\mathrm{Ru}_{6}$ cluster and results in a $-0.34 e$ Bader charge on $\mathrm{Ru}_{6}$ (Table 2). Further away from the $\mathrm{Ru}$ atoms there is a broad $\mathrm{Ru}-\mathrm{Na}$ peak centered around $\sim 3.5 \AA$. This is the clearest outer solvation shell and it constitutes $3.26 \mathrm{Na}^{+}$ neighbors per $\mathrm{Ru}$ atoms $(r<4 \AA$, Table 2$)$. These $\mathrm{Na}^{+}$ions are likely situated here to stabilize the $\mathrm{Cl}^{-}$ions in the inner solvation shell rather than the $\mathrm{Ru}_{6}$ cluster itself. Similar oscillations in ionic concentration have been found in $\mathrm{MD}$ simulations of $\mathrm{LiCl}(l)-\mathrm{MgO}(\mathrm{s})$ interfaces $^{33}$ and $\mathrm{KCl}(l)-$ CdSe(s) interfaces. ${ }^{34}$ Finally, there are two peaks in $\mathrm{g}(r)$ for $\mathrm{Ru}-\mathrm{Cl}$ at $\sim 4.5 \AA$ and $\sim 5.5 \AA$. These peaks correspond to the $\mathrm{Cl}^{-}$ions in the inner solvation shell and their next nearest and third nearest Ru neighbors.

The radial distribution functions for $\mathrm{Ru}_{6}{ }^{2-}+2 \mathrm{Na}^{+}+45 \mathrm{NaCl}$ (Figure 1b) indicate why moving two highly reducing solvated electrons to $\mathrm{Ru}_{6}$ does not stabilize the energy of the cluster (Table 1). The $\mathrm{Ru}_{6}{ }^{2-}$ cluster is negatively charged (Bader charge of $-1.37 e$, Table 2 ), which displaces $\mathrm{Cl}^{-}$ions from the inner solvation shell resulting in a smaller peak at $2.4 \AA$ in $\mathrm{g}(r)$ for 
$\mathrm{Ru}-\mathrm{Cl}$ and a reduction to $0.67 \mathrm{Cl}^{-}$neighbors per $\mathrm{Ru}$ atom $(r<3 \AA$, Table 2$)$. The energy penalty from being less solvated by $\mathrm{Cl}^{-}$ions is only compensated for by a small increase in $\mathrm{Na}^{+}$ions in the outer solvation shell $\left(3.36 \mathrm{Na}^{+}\right.$neighbors per $\mathrm{Ru}$ atoms $\left.(r<4 \AA)\right)$. The negative charge on the $\mathrm{Ru}_{6}{ }^{2-}$ cluster weakens the solvation by the molten $\mathrm{NaCl}$ to such an extend that, at the end of the MD simulation, the $\mathrm{Ru}_{6}{ }^{2-}$ cluster sits at the molten salt surface and is not fully wetted by the molten $\mathrm{NaCl}$ (Figure $1 \mathrm{~b}$ ). In the Supporting Information a movie of the full trajectory is provided.

The inner solvation shell for $\mathrm{Ru}_{6}{ }^{4-}+2 \mathrm{Na}^{+}+45 \mathrm{NaCl}$ (Figure 1c) consists of $0.59 \mathrm{Cl}^{-}$ neighbors per Ru atom $(r<3 \AA$, Table 2$)$ and is only depleted slightly more than $\mathrm{Ru}_{6}{ }^{2-}+2 \mathrm{Na}^{+}+$ $45 \mathrm{NaCl}$. The number of $\mathrm{Na}^{+}$ions in the outer solvation shell is increased to $4.00 \mathrm{Na}^{+}$neighbors per $\mathrm{Ru}$ atom ( $r<4 \AA$, Table 2$)$. Therefore, adding the first two electrons to $\mathrm{Ru}_{6}$ and forming $\mathrm{Ru}_{6}^{2-}$ significantly weakens the interactions with the molten $\mathrm{NaCl}$, while adding the next two electrons and forming $\mathrm{Ru}_{6}^{4-}$ does not correspondingly weaken the interactions. This supports the observation that moving two solvated electrons to $\mathrm{Ru}_{6}$ does not stabilize the cluster, while moving two additional solvated electrons to $\mathrm{Ru}_{6}{ }^{2-}$ and forming $\mathrm{Ru}_{6}{ }^{4-}$ does.

Finally, the radial distribution functions for $\mathrm{Ru}_{3}{ }^{2-}+2 \mathrm{Na}^{+}+45 \mathrm{NaCl}$ are shown in Figure 1d. $T$ he $\mathrm{Ru}_{3}^{2-}$ cluster has more surface area per $\mathrm{Ru}$ atom and is therefore better solvated with 1.07 $\mathrm{Cl}^{-}$neighbors per $\mathrm{Ru}$ atom in the inner solvation shell and $4.99 \mathrm{Na}^{+}$neighbors per $\mathrm{Ru}$ atom in the outer solvation shell. The increased surface area per Ru atom is probably why the molten $\mathrm{NaCl}$ media stabilizes $2 \mathrm{Ru}_{3}{ }^{m / 2-}$ clusters more than $\mathrm{Ru}_{6}{ }^{m-}$ clusters, when compared to the energy difference between $2 \mathrm{Ru}_{3}$ and $\mathrm{Ru}_{6}$ in the gas phase (Table 1 ).

The atomic snapshots of $\mathrm{Ru}_{6}, \mathrm{Ru}_{6}{ }^{2-}$, and $\mathrm{Ru}_{6}{ }^{4-}$ (Figure 1a, b, c) show that the three clusters have adopted the same atomic arrangement (triangular prism geometry), which is also 
the most stable configuration for $\mathrm{Ru}_{6}$ gas phase. ${ }^{27} \mathrm{The}$ smaller $\mathrm{Ru}_{3}{ }^{2-}, \mathrm{Ru}_{3}{ }^{-}$and $\mathrm{Ru}_{3}$ clusters in the molten $\mathrm{NaCl}$ are found to change back and forth between linear configurations (as seen in Figure 1d) and triangular configurations in the MD simulations.
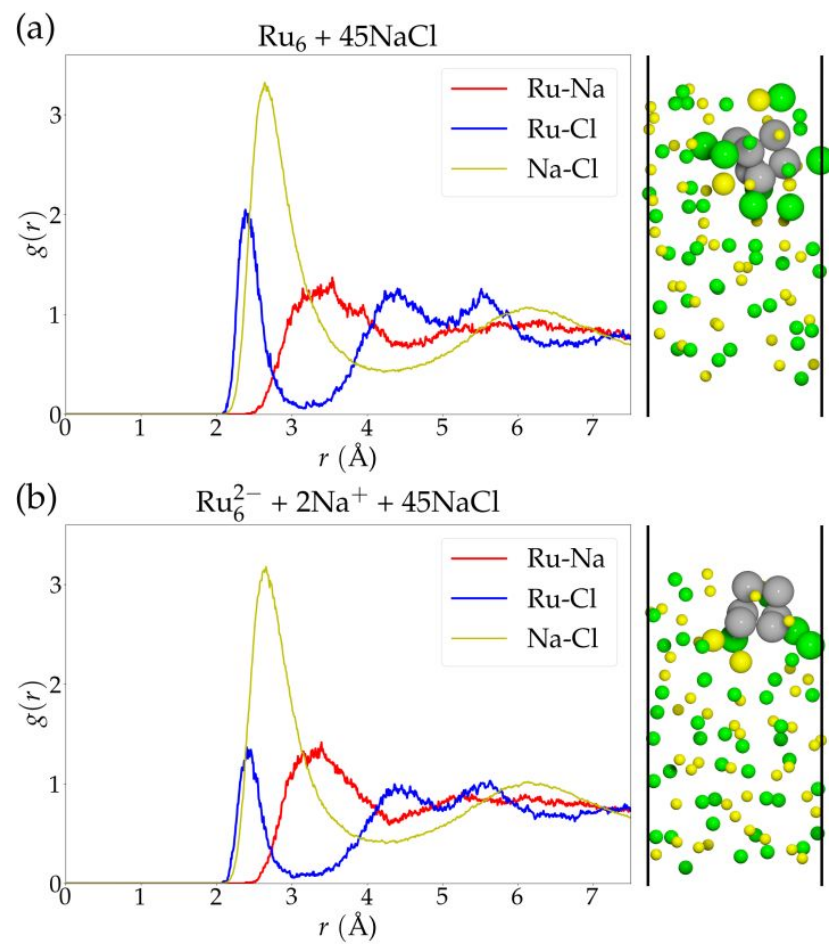

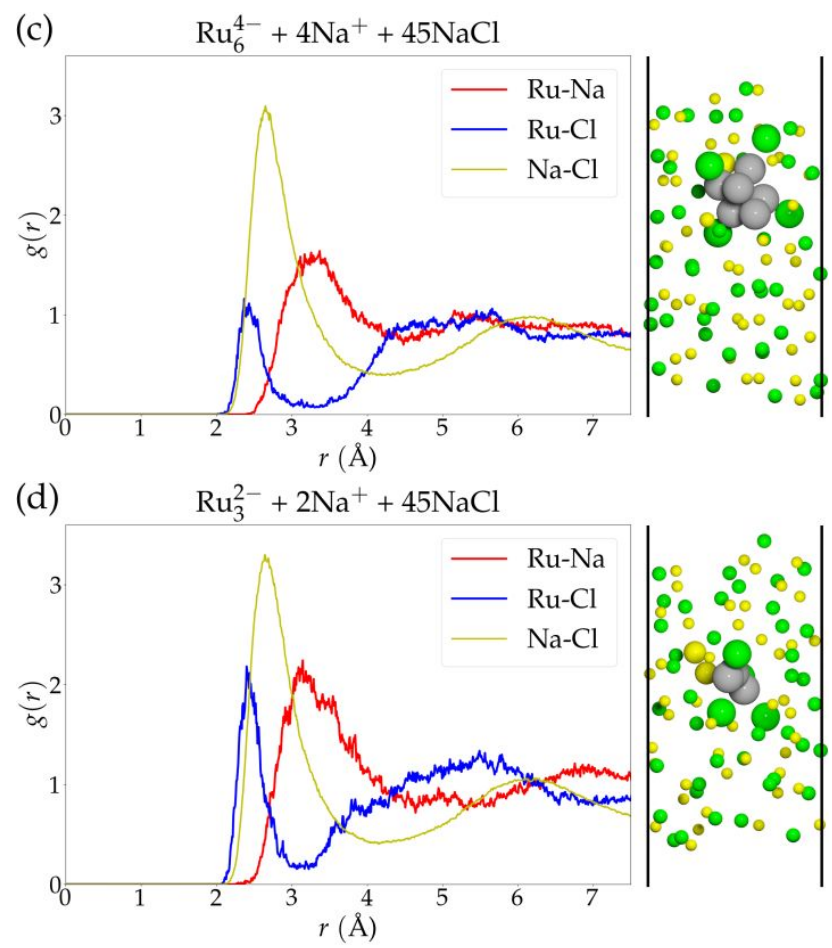

Figure 1: Radial distribution functions $(\mathrm{g}(r))$ and atomic snapshots (at the end of the MD simulations) for (a) $\mathrm{Ru}_{6}+45 \mathrm{NaCl}$, (b) $\mathrm{Ru}_{6}{ }^{2-}+2 \mathrm{Na}^{+}+45 \mathrm{NaCl}$, (c) $\mathrm{Ru}_{6}{ }^{4-}+4 \mathrm{Na}^{+}+45 \mathrm{NaCl}$, and (d) $\mathrm{Ru}_{3}{ }^{2-}+2 \mathrm{Na}^{+}+45 \mathrm{NaCl}$. The radial distribution functions $\left(\mathrm{g}_{A-B}(r)\right)$ are defined such that the number of B neighbors $\left(n_{\mathrm{A}-\mathrm{B}}\right)$ within $r_{\max }$ of each A species is given by $n_{A-B}\left(r<r_{\max }\right)=$ $\int 4 \pi r^{2} \mathrm{~g}_{A-B} \rho_{\text {tot }} \mathrm{dr}$, where $\rho_{\text {tot }}$ is the atomic density in the computational cell (total number of atoms divided by total volume). $\mathrm{Na}^{+}$ions (yellow) and $\mathrm{Cl}^{-}$ions (green) within $3 \AA$ of a $\mathrm{Ru}$ atom have increased radii in the atomic snapshots.

Table 2: Average number of $\mathrm{Cl}$ neighbors (within $3 \AA$ ) and Na neighbors (within $4 \AA$ ) of each $\mathrm{Ru}$ atom. Bader charge on the $\mathrm{Ru}_{n}{ }^{m-}$ clusters.

\begin{tabular}{|l|c|c|c|}
\hline System & $n_{\mathrm{Ru}-\mathrm{Cl}}(<3 \AA)$ & $n_{\mathrm{Ru}-\mathrm{Na}}(<4 \AA)$ & ${\text { Bader charge on } \mathrm{Ru}_{n}{ }^{m-}}$ \\
& & & $(e)$ \\
\hline
\end{tabular}




\begin{tabular}{|l|c|c|c|}
\hline $\mathrm{Ru}_{6}+45 \mathrm{NaCl}$ & 0.98 & 3.26 & -0.34 \\
\hline $\mathrm{Ru}_{6}{ }^{2-}+2 \mathrm{Na}^{+}+45 \mathrm{NaCl}$ & 0.67 & 3.36 & -1.37 \\
\hline $\mathrm{Ru}_{6}{ }^{4-}+4 \mathrm{Na}^{+}+45 \mathrm{NaCl}$ & 0.59 & 4.00 & -2.17 \\
\hline $\mathrm{Ru}_{3}{ }^{2-}+2 \mathrm{Na}^{+}+45 \mathrm{NaCl}$ & 1.07 & 4.99 & -1.14 \\
\hline
\end{tabular}

3.3 Reactivity of $\mathbf{R u}_{n}{ }^{m-}$ - clusters probed by $\mathbf{N}_{2}$ adsorption. In the final part, we study how the reactivity of the $\mathrm{Ru}$ clusters depends on the presence of the molten $\mathrm{NaCl}$, cluster charge, and cluster size. We use molecular $\mathrm{N}_{2}$ adsorption $\left(\mathrm{N}_{2}(\mathrm{~g}) \rightarrow{ }^{*} \mathrm{~N}_{2}\right)$ and dissociative $\mathrm{N}_{2}$ adsorption $\left(\mathrm{N}_{2}(\mathrm{~g}) \rightarrow 2 \mathrm{~N}^{*}\right)$ as a probe for the reactivity. The adsorption energies are collected in Table 3 , while the atomic structures of adsorbed $* \mathrm{~N}_{2}$ or $2 \mathrm{~N} *$ at the end of the MD simulations are depicted in Figure 2. From Bader charge analysis we find that the adsorbed $* \mathrm{~N}_{2}$ molecule has a charge between $-0.7 e$ and $-1.0 e$ and that the two adsorbed $\mathrm{N}^{*}$ species each have a charge of $\sim-$ 1.0 e (Table $\mathrm{S} 2$ in Supporting Information). The Bader charges on $\mathrm{Ru}_{n}{ }^{m-},{ }^{*} \mathrm{~N}_{2}$, and $2 \mathrm{~N}^{*}$ are connected to how well the species are solvated by the $\mathrm{Cl}^{-}$and $\mathrm{Na}^{+}$ions, so we have also collected the number of ion neighbors in Table S3 in Supporting Information. 
${ }^{*} \mathrm{~N}_{2}$
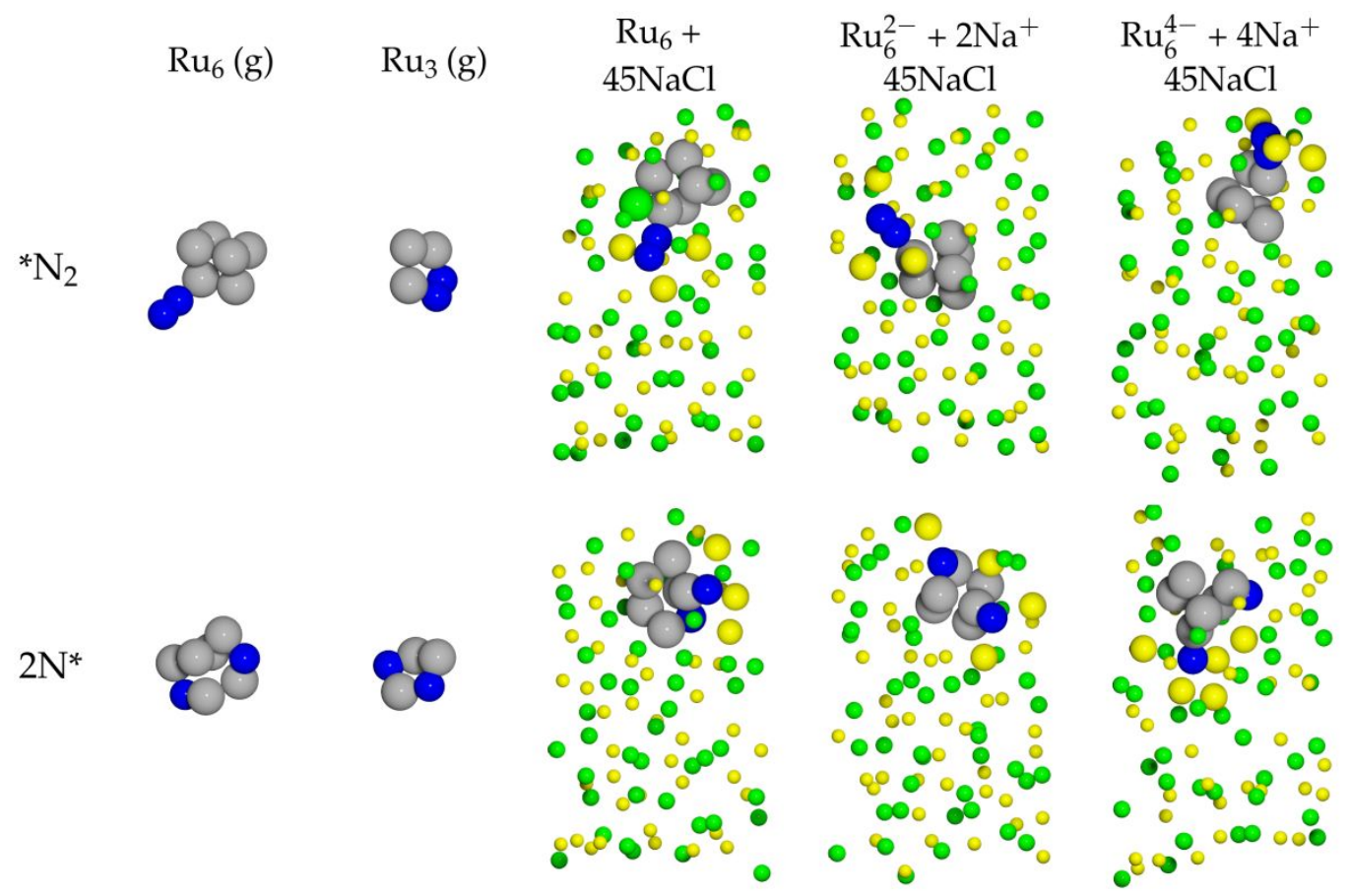

$\mathrm{Ru}_{3}^{2-}+2 \mathrm{Na}^{+}$

$45 \mathrm{NaCl}$
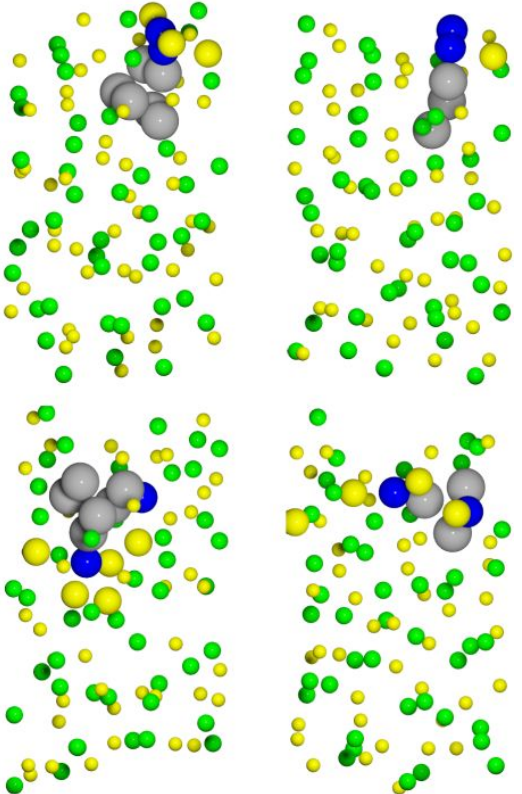

$\circ$

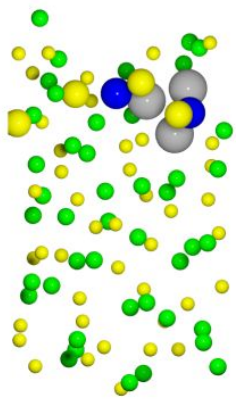

Figure 2: Atomic structures of adsorbed $* \mathrm{~N}_{2}$ and $2 \mathrm{~N} *$ on $\mathrm{Ru}_{3}(\mathrm{~g}), \mathrm{Ru}_{6}(\mathrm{~g}), \mathrm{Ru}_{6}+45 \mathrm{NaCl}, \mathrm{Ru}_{6}{ }^{2-}+$ $2 \mathrm{Na}^{+}+45 \mathrm{NaCl}, \mathrm{Ru}_{6}{ }^{4-}+4 \mathrm{Na}^{+}+45 \mathrm{NaCl}$, and $\mathrm{Ru}_{3}{ }^{2-}+2 \mathrm{Na}^{+}+45 \mathrm{NaCl}$ at the end of the $\mathrm{MD}$ simulations. $\mathrm{Na}^{+}$and $\mathrm{Cl}^{-}$ions within $3 \AA$ of a $\mathrm{N}$ atom have increased radii.

$\mathrm{N}_{2}$ adsorbs on the $\mathrm{Ru}_{6}$ cluster in the gas phase with a molecular adsorption energy of $0.75 \mathrm{eV}$ and a dissociative adsorption energy of $-0.63 \mathrm{eV}$. The smaller $\mathrm{Ru}_{3}(\mathrm{~g})$ cluster is even more reactive, with molecular and dissociative adsorption energies of $-1.14 \mathrm{eV}$ and $-1.60 \mathrm{eV}$, respectively. As a comparison, the adsorption energy of $* \mathrm{~N}_{2}$ and $2 \mathrm{~N}^{*}$ on $\mathrm{Ru}(0001)$ terraces is $0.1 \mathrm{eV}$ and $-0.5 \mathrm{eV}$, respectively, while it is $-0.8 \mathrm{eV}$ and $-0.8 \mathrm{eV}$ on $\mathrm{Ru}(0001)$ step sites (those calculations were performed with the RPBE functional). ${ }^{35}$ The gas phase $\mathrm{Ru}_{6}$ cluster has a comparable reactivity to $\mathrm{Ru}(0001)$ step sites and it is believed that the step sites dominate in $\mathrm{N}_{2}$ activation on $\mathrm{Ru}(0001)$ single crystals. ${ }^{36,37}$ 
When the $\mathrm{Ru}_{6}$ cluster is situated in the molten $\mathrm{NaCl}$ media it loses most of its reactivity due to the interactions between $\mathrm{Ru}_{6}$ and $\mathrm{Cl}^{\text {}}$, which compete with the binding of $* \mathrm{~N}_{2}$ or $2 \mathrm{~N} *$ to $\mathrm{Ru}_{6}$. The molecular and dissociative $\mathrm{N}_{2}$ adsorption energies are therefore only $-0.3 \mathrm{eV}$ and -0.1 $\mathrm{eV}$, respectively. Interestingly, charging the $\mathrm{Ru}_{6}$ cluster with electrons and forming $\mathrm{Ru}_{6}{ }^{2-}$ or $\mathrm{Ru}_{6}{ }^{4-}$ make the clusters very reactive. The $\mathrm{Ru}_{6}{ }^{2-}$ cluster in molten $\mathrm{NaCl}$ is found to be the most reactive cluster investigated with the most stable adsorption energies for both ${ }^{*} \mathrm{~N}_{2}(-2.2 \mathrm{eV})$ and $2 \mathrm{~N} *(-$ $3.4 \mathrm{eV})$. The reason $\mathrm{Ru}_{6}^{2-}$ is the most reactive cluster likely relates back to the small amount of $\mathrm{Cl}^{-}$ions in the first solvation shell around the $\mathrm{Ru}_{6}{ }^{2-}$ cluster prior to $\mathrm{N}_{2}$ adsorption. When ${ }^{*} \mathrm{~N}_{2}$ or $2 \mathrm{~N}^{*}$ is adsorbed, they take electrons from the $\mathrm{Ru}_{6}{ }^{2-}$ cluster such that the Bader charge on the cluster is changed from $-1.37 e$ without adsorbents to $-0.80 e$ with $* \mathrm{~N}_{2}$ and $0.19 e$ with $2 \mathrm{~N} *$. As the cluster becomes less negatively charged, the amount of $\mathrm{Cl}^{-}$ions in the first solvation shell is increased from $0.67 \mathrm{Cl}^{-}$per $\mathrm{Ru}$ atom to $0.76 \mathrm{Cl}^{-}$per Ru atom with ${ }^{*} \mathrm{~N}_{2}$ and $0.74 \mathrm{Cl}^{-}$per $\mathrm{Ru}$ atom with $2 \mathrm{~N}^{*}$. The $* \mathrm{~N}_{2}$ and $2 \mathrm{~N}^{*}$ species are hereby indirectly stabilized by the increased interactions between $\mathrm{Cl}^{-}$and $\mathrm{Ru}$ atoms.

The $\mathrm{Ru}_{6}{ }^{4-}$ cluster is also more reactive than the non-charged $\mathrm{Ru}_{6}$ cluster in molten $\mathrm{NaCl}$, with adsorption energies of $-1.2 \mathrm{eV}$ for $* \mathrm{~N}_{2}$ and $-1.9 \mathrm{eV}$ for $2 \mathrm{~N} *$. The $\mathrm{Ru}_{6}{ }^{4}$ cluster is more negatively charged than $\mathrm{Ru}_{6}{ }^{2-}$ (Table 2), and it still has significant negative charge after $* \mathrm{~N}_{2}$ adsorption $(-1.90 e)$ and $2 \mathrm{~N}^{*}$ adsorption $(-0.51 e)$. This means that $\mathrm{Ru}_{6}{ }^{4-}$ does not experience an increase of $\mathrm{Cl}^{-}$ions in the first solvation shell $\left(0.47 \mathrm{Cl}^{-}\right.$per $\mathrm{Ru}$ atom with ${ }^{*} \mathrm{~N}_{2}$ and $0.57 \mathrm{Cl}^{-}$per $\mathrm{Ru}$ atom with $\left.2 \mathrm{~N}^{*}\right)$ compared to before $\mathrm{N}_{2}$ adsorption $\left(0.59 \mathrm{Cl}^{-}\right.$per $\mathrm{Ru}$ atom).

Table 3: Molecular $\left(E_{\mathrm{ad}}\left(* \mathrm{~N}_{2}\right), \mathrm{N}_{2}(\mathrm{~g}) \rightarrow{ }^{*} \mathrm{~N}_{2}\right)$ and dissociative $\left(E_{\mathrm{ad}}\left(2 \mathrm{~N}^{*}\right), \mathrm{N}_{2}(\mathrm{~g}) \rightarrow 2 \mathrm{~N}^{*}\right)$ adsorption energies for $\mathrm{N}_{2}$ on the $\mathrm{Ru}_{n}{ }^{m-}$ clusters. 


\begin{tabular}{|c|c|c|c|}
\hline $\mathbf{R} \mathbf{u}_{n}{ }^{m-}$ cluster & Reaction media & $E_{\mathrm{ad}}\left(* \mathbf{N}_{2}\right)$ & $E_{\mathrm{ad}}\left(2 \mathrm{~N}^{*}\right)$ \\
\hline $\mathbf{R} \mathbf{u}_{6}$ & gas phase & $-0.75 \mathrm{eV}$ & $-0.63 \mathrm{eV}$ \\
\hline $\mathbf{R} \mathbf{u}_{3}$ & gas phase & $-1.14 \mathrm{eV}$ & $-1.60 \mathrm{eV}$ \\
\hline $\mathbf{R} \mathbf{u}_{6}$ & molten $\mathrm{NaCl}$ & $-0.3 \mathrm{eV}$ & $-0.1 \mathrm{eV}$ \\
\hline $\mathrm{Ru}_{6}{ }^{2-}$ & molten $\mathrm{NaCl}$ & $-2.2 \mathrm{eV}$ & $-3.4 \mathrm{eV}$ \\
\hline $\mathrm{Ru}_{6}{ }^{4-}$ & molten $\mathrm{NaCl}$ & $-1.2 \mathrm{eV}$ & $-1.9 \mathrm{eV}$ \\
\hline $\mathbf{R u}_{3}{ }^{2-}$ & molten $\mathrm{NaCl}$ & $-1.1 \mathrm{eV}$ & $-3.3 \mathrm{eV}$ \\
\hline $\mathbf{R} \mathbf{u}_{3}$ & molten $\mathrm{NaCl}$ & $-1.3 \mathrm{eV}$ & $-1.8 \mathrm{eV}$ \\
\hline
\end{tabular}

In Figure 3, we have plotted the molecular $* \mathrm{~N}_{2}$ adsorption energy versus the dissociative $2 \mathrm{~N}^{*}$ adsorption energy for all studied Ru clusters (the numbers reported in Table 3 ). It is seen that there is a clear scaling relation $\left(E_{\mathrm{ad}}\left(2 \mathrm{~N}^{*}\right)=a E_{\mathrm{ad}}\left(* \mathrm{~N}_{2}\right)+b\right)$ between molecular adsorption and dissociative adsorption energy pairs except for adsorption on $\mathrm{Ru}_{3}{ }^{2-}$. The reaction energies could have an error of up to $\pm 0.3 \mathrm{eV}$ due to limited AIMD sampling (estimated from the cumulative reaction energies plotted in Figure S2). However, such an error would not significantly change the scaling relation or move $\mathrm{Ru}_{3}{ }^{2-}$ on to the scaling line. Scaling relations between adsorption energies are well known, ${ }^{38-40}$ but it is somewhat surprising that the same scaling relation exist for adsorption on the $\mathrm{Ru}$ clusters in gas phase and adsorption on the $\mathrm{Ru}$ clusters in molten $\mathrm{NaCl}$. It has been proposed that "electrolyte engineering" could be a way of breaking scaling relations, ${ }^{41}$ but since we find the same scaling relation with and without the molten $\mathrm{NaCl}$ reaction media, this approach may not be so promising. 


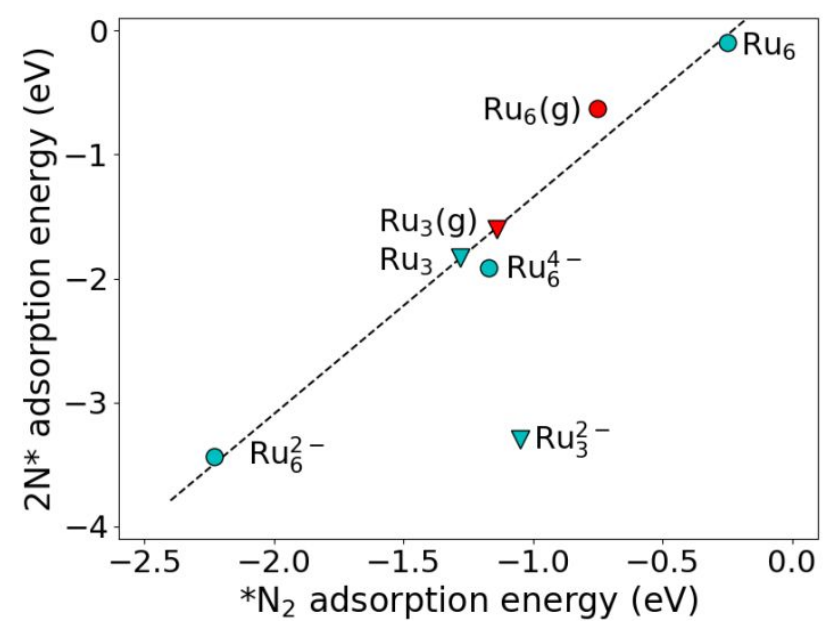

Figure 3: Relation between $E_{\mathrm{ad}}\left(* \mathrm{~N}_{2}\right)$ and $E_{\mathrm{ad}}\left(2 \mathrm{~N}^{*}\right)$ from Table 3. Red points represent gas phase $\mathrm{Ru}$ clusters, circles represent $\mathrm{Ru}_{6}{ }^{m-}$ clusters, and triangles represent $\mathrm{Ru}_{3}{ }^{m-}$ clusters. The fitted line $E_{\mathrm{ad}}(2 \mathrm{~N} *)=1.7 E_{\mathrm{ad}}\left(* \mathrm{~N}_{2}\right)+0.4 \mathrm{eV}$ indicates the existence of a linear scaling relation between molecular adsorption $\left(E_{\mathrm{ad}}\left(* \mathrm{~N}_{2}\right)\right)$ and dissociate adsorption $\left(E_{\mathrm{ad}}\left(2 \mathrm{~N}^{*}\right)\right)$ for all energy pairs except for $\mathrm{Ru}_{3}{ }^{2-}$ (not included in the fit).

In Figure 3, the energies for ${ }^{*} \mathrm{~N}_{2}$ and $2 \mathrm{~N}^{*}$ adsorption on $\mathrm{Ru}_{3}{ }^{2-}$ fall outside the general scaling relation. One possible explanation is that the $* \mathrm{~N}_{2}$ species in $* \mathrm{~N}_{2}+\mathrm{Ru}_{3}{ }^{2-}+2 \mathrm{Na}^{+}+45 \mathrm{NaCl}$ is not well solvated and therefore has less stable adsorption energy than expected from the adsorption energy of $2 \mathrm{~N}^{*}$ in $2 \mathrm{~N}^{*}+\mathrm{Ru}_{3}{ }^{2-}+2 \mathrm{Na}^{+}+45 \mathrm{NaCl}$ (which is well solvated). This is supported by the observation that the $\mathrm{N}$ atoms in $* \mathrm{~N}_{2}+\mathrm{Ru}_{3}{ }^{2-}+2 \mathrm{Na}^{+}+45 \mathrm{NaCl}$ have the lowest number of $\mathrm{Na}^{+}$neighbors per $\mathrm{N}$ atom and one of the least negative Bader charges for a $* \mathrm{~N}_{2}$ species $(-0.69 e)$. This data is presented in Table S2 and S3 in the Supporting Information.

The surprising relation for $* \mathrm{~N}_{2}$ and $2 \mathrm{~N} *$ adsorption on $\mathrm{Ru}_{3}{ }^{2-}$ compelled us to also consider $* \mathrm{~N}_{2}$ and $2 \mathrm{~N} *$ adsorption on a neutral $\mathrm{Ru}_{3}$ cluster in molten $\mathrm{NaCl}$. The AIMD simulations for $\mathrm{Ru}_{3}+45 \mathrm{NaCl},{ }^{*} \mathrm{~N}_{2}+\mathrm{Ru}_{3}+45 \mathrm{NaCl}$, and $2 \mathrm{~N} *+\mathrm{Ru}_{3}+45 \mathrm{NaCl}$ were initialized 
from the endpoint of the AIMD simulations for $* \mathrm{~N}_{2}$ and $2 \mathrm{~N}^{*}$ adsorption on $\mathrm{Ru}_{3}{ }^{2-}$, but with two $\mathrm{Na}$ atoms removed from the systems. The adsorption energies are $-1.3 \mathrm{eV}$ for $* \mathrm{~N}_{2}$ and $-1.8 \mathrm{eV}$ for $2 \mathrm{~N}^{*}$ (Table 3), which places the adsorption energies neatly on the scaling line in Figure $3 . \mathrm{N}_{2}$ adsorption on the neutral $\mathrm{Ru}_{3}$ cluster therefore emphasizes the strangeness of the $\mathrm{Ru}_{3}{ }^{2-}$ case and indicates that both the size and the charge of the $\mathrm{Ru}_{3}{ }^{2-}$ cluster is required to get the unusual behavior.

\section{Summary}

$\mathrm{Ru}_{6}$ and $\mathrm{Ru}_{3}$ clusters become negatively charged when they are suspended in a molten $\mathrm{NaCl}$ film containing solvated electrons. Furthermore, our results indicate that such charging will affect the stability and reactivity of small Ru clusters.

The interactions between the $\mathrm{Ru}$ clusters and the molten $\mathrm{NaCl}$ are very important for the stability of the clusters. The neutral $\mathrm{Ru}_{6}$ cluster has an inner solvation shell of $\mathrm{Cl}^{-}$ions and an outer solvation shell of $\mathrm{Na}^{+}$ions. The negative charge on $\mathrm{Ru}_{6}^{2-}$ reduces the number of $\mathrm{Cl}^{-}$ions in the inner solvation shell and $\mathrm{Ru}_{6}^{2-}$ is therefore not stabilized by the solvated electrons. The inner solvation shell around $\mathrm{Ru}_{6}{ }^{4-}$ is not depleted much further and $\mathrm{Ru}_{6}{ }^{4-}$ is stabilized compared to $\mathrm{Ru}_{6}$ and $\mathrm{Ru}_{6}{ }^{2-}$.

Suspending $\mathrm{Ru}_{6}$ in molten $\mathrm{NaCl}$ decreases its reactivity for $\mathrm{N}_{2}$ adsorption compared to $\mathrm{Ru}_{6}$ in the gas phase; however, charging the $\mathrm{Ru}_{6}$ cluster with two or four electrons restores high reactivity. The molecular and dissociative $\mathrm{N}_{2}$ adsorption energies are connected by a scaling relation, which holds for both $\mathrm{Ru}$ clusters in the gas phase and charged $\mathrm{Ru}$ clusters in molten $\mathrm{NaCl}$. The only exception is $\mathrm{N}_{2}$ adsorption on $\mathrm{Ru}_{3}{ }^{2-}$ in molten $\mathrm{NaCl}$.

Compared to bulk Ru metal, the small Ru clusters are not stable; however, it may still be possible to synthesize small clusters from a ruthenium salt precursor (such as $\mathrm{RuCl}_{3}$ ) and $\mathrm{Na}$ 
metal as the reductant. In such a synthesis pathway the kinetic stability of the clusters against agglomeration will be important and then it may be beneficial to have negative charged clusters. In our previous study of solvated electrons, we found that molten $\mathrm{LiCl}$ stabilizes negative species much better than does molten $\mathrm{NaCl} .{ }^{19}$ However, here we have intentionally chosen molten $\mathrm{NaCl}$ instead of molten $\mathrm{LiCl}$, because we wanted to prohibit formation of $\mathrm{N}^{3-}$ ions in the molten salt. $\mathrm{Na}_{3} \mathrm{~N}$ is thermally unstable whereas $\mathrm{Li}_{3} \mathrm{~N}$ is thermally stable. ${ }^{42}$ The same holds for $\mathrm{NaH}$ and $\mathrm{LiH},{ }^{43}$ which would be important if hydrogen is included in the attempt to form ammonia. Ammonia synthesis would of course require molten salt eutectic mixtures with lower melting point than $\mathrm{NaCl}(1074 \mathrm{~K})$.

\section{Supporting Information}

Movies showing the full trajectories of the MD simulations with $\mathrm{Ru}$ clusters in molten $\mathrm{NaCl}$. Equilibration time $\left(t_{0}\right)$ and sampling time $\left(t-t_{0}\right)$ for the MD simulations. Average Bader charges on the $\mathrm{Ru}_{n}{ }^{m-}$ clusters and adsorbed $* \mathrm{~N}_{2}$ or $2 \mathrm{~N}^{*}$ species. Average number of $\mathrm{Na}^{+}$or $\mathrm{Cl}^{-}$ion neighbors to each $\mathrm{N}$ atom or $\mathrm{Ru}$ atom. Plot of cumulative reaction energies as a function of sampling time for the formation $\mathrm{Ru}_{6}{ }^{m-}$ and $\mathrm{Ru}_{3}{ }^{m / 2-}$ clusters. Plot of cumulative adsorption energies as a function of sampling time for $* \mathrm{~N}_{2}$ and $2 \mathrm{~N}^{*}$ adsorption.

\section{Acknowledgments}

Financial support was provided the Department of Energy, Office of Science, Office of Basic Energy Sciences DE-FG03-89ER14048, and by an individual postdoctoral grant from VILLUM FONDEN. We acknowledge support from the Center for Scientific Computing from the CNSI, MRL: an NSF MRSEC (DMR-1720256) and NSF CNS-0960316. 


\section{References}

(1) Liu, X.; Fechler, N.; Antonietti, M. Salt Melt Synthesis of Ceramics, Semiconductors and Carbon Nanostructures. Chem. Soc. Rev. 2013, 42 (21), 8237-8265.

(2) Zhao, H.; Yu, C.; You, H.; Yang, S.; Guo, Y.; Ding, B.; Song, X. A Green Chemical Approach for Preparation of $\mathrm{Pt}_{\mathrm{x}} \mathrm{Cu}_{\mathrm{y}}$ Nanoparticles with a Concave Surface in Molten Salt for Methanol and Formic Acid Oxidation Reactions. J. Mater. Chem. 2012, 22 (11), $4780-4789$.

(3) Qiu, P.; Bi, J.; Zhang, X.; Yang, S. Organics- and Surfactant-Free Molten Salt Medium Controlled Synthesis of Pt-M (M = Cu and Pd) Bi- and Trimetallic Nanocubes and Nanosheets. ACS Sustain. Chem. Eng. 2017, 5 (5), 4205-4213.

(4) Sun, G.-D.; Wang, K.-F.; Ji, X.-P.; Liu, J.-K.; Zhang, H.; Zhang, G.-H. Preparation of Ultrafine/Nano Mo Particles via NaCl-Assisted Hydrogen Reduction of Different-Sized $\mathrm{MoO}_{2}$ Powders. Int. J. Refract. Met. Hard Mater. 2019, 80, 243-252.

(5) Rieke, R. D. Preparation of Highly Reactive Metal Powders and Their Use in Organic and Organometallic Synthesis. Acc. Chem. Res. 1977, 10 (8), 301-306.

(6) Ding, J.; Tsuzuki, T.; McCormick, P. G.; Street, R. Ultrafine Co and Ni Particles Prepared by Mechanochemical Processing. J. Phys. D. Appl. Phys. 1996, 29 (9), 2365-2369.

(7) Tsuzuki, T.; McCormick, P. G. Mechanochemical Synthesis of Nanoparticles. J. Mater. Sci. 2004, 39 (16), 5143-5146. 
(8) Bredig, M. A. Mixtures of Metals with Molten Salts (ORNL-3391)

http://moltensalt.org/references/static/downloads/pdf/ORNL-3391.pdf (accessed Feb 14, 2019).

(9) Bredig, M. A.; Johnson, J. W.; Smith, W. T. Miscibility of Liquid Metals with Salts. I.

The Sodium-Sodium Halide Systems. J. Am. Chem. Soc. 1955, 77 (2), 307-312.

(10) Bredig, M. A.; Bronstein, H. R. Miscibility of Liquid Metals with Salts. IV. The SodiumSodium Halide Systems at High Temperatures. J. Phys. Chem. 1960, 64 (1), 64-67.

(11) Liu, M.; Masset, P.; Gray-Weale, A. Solubility of Sodium in Sodium Chloride: A Density Functional Theory Molecular Dynamics Study. J. Electrochem. Soc. 2014, 161 (8), E3042-E3048.

(12) Tanabe, K.; Hölderich, W. F. Industrial Application of Solid Acid-Base Catalysts. Appl. Catal. A Gen. 1999, 181 (2), 399-434.

(13) Hattori, H. Solid Base Catalysts: Fundamentals and Their Applications in Organic Reactions. Appl. Catal. A Gen. 2015, 504, 103-109.

(14) Davis, R. J.; Doskocil, E. J.; Bordawekar, S. Structure/Function Relationships for Basic Zeolite Catalysts Containing Occluded Alkali Species. Catal. Today 2000, 62 (2), 241247.

(15) Davis, R. J. New Perspectives on Basic Zeolites as Catalysts and Catalyst Supports. J. Catal. 2003, $216(1), 396-405$.

(16) Nielsen, A. Review of Ammonia Catalysis. Catal. Rev. 1971, 4 (1), 1-26. 
(17) Hinrichsen, O.; Rosowski, F.; Hornung, A.; Muhler, M.; Ertl, G. The Kinetics of Ammonia Synthesis over Ru-Based Catalysts: 1. The Dissociative Chemisorption and Associative Desorption of $\mathrm{N}_{2}$. J. Catal. 1997, 165 (1), 33-44.

(18) Kuganathan, N.; Hosono, H.; Shluger, A. L.; Sushko, P. V. Enhanced $\mathrm{N}_{2}$ Dissociation on Ru-Loaded Inorganic Electride. J. Am. Chem. Soc. 2014, 136 (6), 2216-2219.

(19) Kristoffersen, H. H.; Metiu, H. Chemistry of Solvated Electrons in Molten Alkali Chloride Salts. J. Phys. Chem. C 2018, 122 (34), 19603-19612.

(20) Qi, W. H.; Wang, M. P. Size Effect on the Cohesive Energy of Nanoparticle. J. Mater. Sci. Lett. 2002, 21 (22), 1743-1745.

(21) Kresse, G.; Hafner, J. Ab Initio Molecular-Dynamics Simulation of the Liquid-MetalAmorphous-Semiconductor Transition in Germanium. Phys. Rev. B 1994, 49 (20), 1425114269.

(22) Kresse, G.; Hafner, J. Ab Initio Molecular Dynamics for Liquid Metals. Phys. Rev. B 1993, $47(1), 558-561$.

(23) Kresse, G.; Furthmüller, J. Efficiency of Ab-Initio Total Energy Calculations for Metals and Semiconductors Using a Plane-Wave Basis Set. Comput. Mater. Sci. 1996, 6 (1), 1550.

(24) Kresse, G.; Furthmüller, J. Efficient Iterative Schemes for Ab Initio Total-Energy Calculations Using a Plane-Wave Basis Set. Phys. Rev. B 1996, 54 (16), 11169-11186.

(25) Perdew, J. P.; Burke, K.; Ernzerhof, M. Generalized Gradient Approximation Made Simple. Phys. Rev. Lett. 1996, 77 (18), 3865-3868. 
(26) Grimme, S.; Antony, J.; Ehrlich, S.; Krieg, H. A Consistent and Accurate Ab Initio Parametrization of Density Functional Dispersion Correction (DFT-D) for the 94 Elements H-Pu. J. Chem. Phys. 2010, 132 (15), 154104.

(27) Demiroglu, I.; Yao, K.; Hussein, H. A.; Johnston, R. L. DFT Global Optimization of GasPhase Subnanometer Ru-Pt Clusters. J. Phys. Chem. C 2017, 121 (20), 10773-10780.

(28) Sangster, J.; Pelton, A. D. Phase Diagrams and Thermodynamic Properties of the 70 Binary Alkali Halide Systems Having Common Ions. J. Phys. Chem. Ref. Data 1987, 16 (3), 509-561.

(29) Nosé, S. A Unified Formulation of the Constant Temperature Molecular Dynamics Methods. J. Chem. Phys. 1984, 81 (1), 511-519.

(30) Bader, R. F. W. Atoms In Molecules: A Quantum Theory; Clarendon: Oxford, UK, 1990.

(31) Sanville, E.; Kenny, S. D.; Smith, R.; Henkelman, G. Improved Grid-Based Algorithm for Bader Charge Allocation. J. Comput. Chem. 2007, 28 (5), 899-908.

(32) Tang, W.; Sanville, E.; Henkelman, G. A Grid-Based Bader Analysis Algorithm without Lattice Bias. J. Phys. Condens. Matter 2009, 21 (8), 84204.

(33) Kristoffersen, H. H.; Metiu, H. Molten LiCl Layer Supported on MgO: Its Possible Role in Enhancing the Oxidative Dehydrogenation of Ethane. J. Phys. Chem. C 2015, 119 (16), $8681-8691$

(34) Zhang, H.; Dasbiswas, K.; Ludwig, N. B.; Han, G.; Lee, B.; Vaikuntanathan, S.; Talapin, D. V. Stable Colloids in Molten Inorganic Salts. Nature 2017, 542, 328. 
(35) Dahl, S.; Logadottir, A.; Egeberg, R. C.; Larsen, J. H.; Chorkendorff, I.; Törnqvist, E.; Nørskov, J. K. Role of Steps in $\mathrm{N}_{2}$ Activation on Ru(0001). Phys. Rev. Lett. 1999, 83 (9), $1814-1817$.

(36) Dahl, S.; Törnqvist, E.; Chorkendorff, I. Dissociative Adsorption of $\mathrm{N}_{2}$ on Ru(0001): A Surface Reaction Totally Dominated by Steps. J. Catal. 2000, 192 (2), 381-390.

(37) Honkala, K.; Hellman, A.; Remediakis, I. N.; Logadottir, A.; Carlsson, A.; Dahl, S.;

Christensen, C. H.; Nørskov, J. K. Ammonia Synthesis from First-Principles Calculations. Science 2005, 307 (5709), 555-558.

(38) Nørskov, J. K.; Bligaard, T.; Logadottir, A.; Bahn, S.; Hansen, L. B.; Bollinger, M.; Bengaard, H.; Hammer, B.; Sljivancanin, Z.; Mavrikakis, M.; Xu, Y.; Dahl, S.; Jacobsen, C. J. H. Universality in Heterogeneous Catalysis. J. Catal. 2002, 209 (2), 275-278.

(39) Logadottir, A.; Rod, T. H.; Nørskov, J. K.; Hammer, B.; Dahl, S.; Jacobsen, C. J. H. The Brønsted-Evans-Polanyi Relation and the Volcano Plot for Ammonia Synthesis over Transition Metal Catalysts. J. Catal. 2001, 197 (2), 229-231.

(40) Vojvodic, A.; Medford, A. J.; Studt, F.; Abild-Pedersen, F.; Khan, T. S.; Bligaard, T.; Nørskov, J. K. Exploring the Limits: A Low-Pressure, Low-Temperature Haber-Bosch Process. Chem. Phys. Lett. 2014, 598, 108-112.

(41) Montoya, J. H.; Seitz, L. C.; Chakthranont, P.; Vojvodic, A.; Jaramillo, T. F.; Nørskov, J. K. Materials for Solar Fuels and Chemicals. Nat. Mater. 2016, 16, 70.

(42) Vajenine, G. V. Plasma-Assisted Synthesis and Properties of $\mathrm{Na}_{3} \mathrm{~N}$. Inorg. Chem. 2007, $46(13), 5146-5148$. 
(43) Wietelmann, U.; Felderhoff, M.; Rittmeyer, P. Hydrides. In Ullmann's Encyclopedia of Industrial Chemistry; Wiley-VCH Verlag GmbH \& Co. KGaA, Weinheim, 2016. 


\section{TOC}

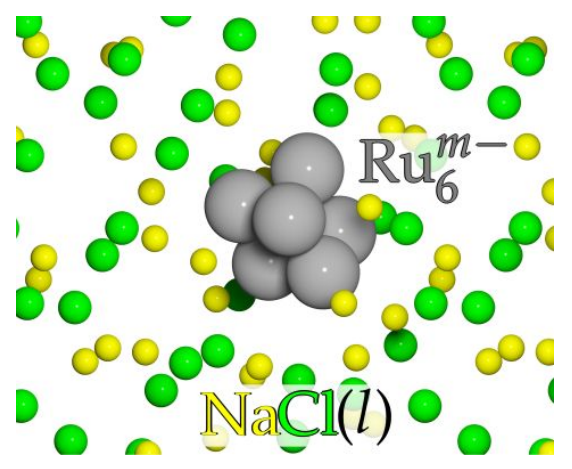

